\title{
Covid Behavior as an Indicator of Political Loyalty
}

\author{
Ibragimov Radiy Nazibovich ${ }^{1, *}$
}

\author{
Katanov Khakass State University, Abakan, Russia \\ ${ }^{*}$ Corresponding author.Email: dison1@mail.ru
}

\begin{abstract}
The two years of the COVID-19 pandemic provided ample material for the analysis of social behavior and its various tactics in a pandemic crisis. Given the role of the state in organizing protective measures, these tactics can be understood as direct or indirect reactions of different categories of the population. The article suggests building a correlation between the typology of covid behavior and the phenomenon of political loyalty, the morphology of which is in fact more complex and deeper than the simplest survey techniques can show. On the basis of empirical research, combining data analysis, interviews and observation, several social types with specific tactics congruent with types of political loyalty are identified.
\end{abstract}

Keywords: Covid behavior, Loyalty, Social sanity, Communicative message.

\section{INTRODUCTION}

In 2016 there was an event that directly affected the reputation of American empirical sociology, for which, nevertheless, domestic sociologists had to justify themselves. Namely: U.S. citizens, contrary to the predictions of respected sociological agencies, elected D. Trump as president. Explanations for this «misunderstanding» were varied and diverse. Among others, there was the assumption that today's Americans are no longer as innocent respondents as they were in the industrial era of the 1920s and 1930s; that they think one thing, put another in their questionnaires, and do something else; that the time has come to think seriously about the methodological retooling of social sciences that try to understand and connect people's thoughts, words, and actions.

Sic! With a certain amount of schadenfreude we would like to record that the American respondent of the postmodern era has approached the Russian (post-Soviet) respondent, who, it seems, has not been out of this era since the times of Ivan III, in terms of the complexity of its organization. The sociocultural code of the Russian population was, according to a number of researchers, significantly influenced by serfdom, shaping such features of worldview and social behavior as distrust of elites and imitation of loyalty. This, in turn, gave rise to unpredictable zigzags of Russian history, unexpected bursts of protest activity, which even A.S. Pushkin called «the terrible Russian revolt».

The February Revolution of 1917 was unpredictable - while in Russia and in exile, in the camps of monarchists, liberals and leftist revolutionaries there worked insightful and profound analysts (P.A. Sorokin, M.I. Tugan-Baranovsky, P.Y. Struve, G.V. Plekhanov, V.I. Ulyanov-Lenin and many others). The collapse of the Soviet Union was also unpredictable for both domestic and foreign researchers.

The famous formula «the top cannot - the bottom will not» works as a forecasting methodology only if the «bottoms» openly express their discontent and their readiness to translate this discontent into something. If the population, remembering "Yuriev Day» and Stalinist repression, only imitates devotion to the ideals of communism, then predicting when the «volume to revolt» will outweigh the «volume to imitate devotion» becomes a thankless task for sociology.

We do not aim to find out what factors have contributed to the new quality of «to be canny» in the American respondent. Our goal is to conduct a primary testing of loyalty measurement through a specific indicator that is indirectly related to the phenomenon of loyalty. The COVID-19 pandemic, or to be more precise, the variety of public reactions to government initiatives to combat it, which may have come as a surprise to lockdown enthusiasts, was a good thing. [1]

The immediate reason for reflection was the comparison of two obvious facts - indicators of political sympathy of the population to the leadership of the country, on the one hand, and indicators of voluntary vaccination of the same population. It is impossible to ignore the connection of these indices, [2.] since the leadership, headed personally by the President, during 
two years, using mass-media of all calibers, has been bombarding the population, among which it, the leadership, has sociologically verified authority, with requests and recommendations to be vaccinated against the pandemic. The President's approval rating fluctuated between 62-67\% between June and October 2021 (https://wciom.ru/ratings/doverie-politikam/).

The results of the requests and recommendations are given. They are deplorable. [3, P.150] The question is, what does this «celebration of disobedience» mean communicatively? What is the content of the reciprocal message if the loyalty index is not just not confirmed by the indirect indicator, but rather contradicts it?

\section{MATERIALS AND METHODS}

The empirical basis of our study consisted of several arrays. First, we used information on the population's attitudes toward anti-COVID restrictions on a national scale, as presented in the Rosstat [4], VCIOM (AllRussian Public Opinion Research Center), and FOM (Public Opinion Foundation) bulletins. The results of the monitoring of political attitudes and expectations were also taken there, which allowed for a correlation analysis in macro-social, country-scale terms.

Second, a research project focused on regional human capital reproduction issues conducted 1.216 formalized interviews over the 2019-2021 period to address the population's response to the pandemic itself, as well as the state's prevention and prevention efforts. Young people (high school and university students and secondary vocational education students) were interviewed about their personal and family feelings during the pandemic self-isolation period (summer 2019; autumn 2021). This cohort was chosen, among other reasons, as the most active and intolerant of deprivation. Along with the question about the feeling and attitude towards the initiatives of the authorities, the guide included a question about what measures should be taken to normalize the situation, according to the respondents themselves. It was these answers that were taken into account as a kind of social request.

The results of this program were accompanied by the results of another procedure, observation. Fixation on the indicator of social behavior - wearing a mask - was carried out on a part of the same sample as during the interviewing. The «reciprocal attendance» legend allowed 361 cases to be tracked, which subsequently became the basis for conclusions about the connection between declarative and practical components of social behavior.

The use of extrapolation is impossible without involving the axiomatic method. [see e.g. 5, pp. 64-65] The following statements appear as postulates, which were put in the basis of our inferences.

First, by now (late 2021) public attitudes toward the pandemic and measures to prevent it are no longer based on awareness and have finally become a matter of conviction, of belief.

Secondly, the population's attitude towards specific positions and actions of specific authorities can be inductively extrapolated to the state of loyalty to these subjects in general. We intend to proceed from these provisions in the future.

\section{RESULTS AND DISCUSSION}

This year, 2021, the information situation is fundamentally different than it was a year or a year and a half ago. Back then, at the beginning of 2020, the element of uncertainty was much stronger. It was not clear what was the genetic nature of the disease, the degree of danger, medical support, how and on what scale to organize the hospital bed fund and the work of medical staff, etc. [6]

Countries were just beginning to experiment with pandemic resistance regimes. Notable here is the example of the United Kingdom, where the initial course was to build up natural immunity, and later the state was forced to undertake a centralized effort to combat COVID-19. This example is noteworthy because, at least declaratively, Great Britain is an example of a liberal socioeconomic model. Metaphorically, the role of the state in this model is reduced to the image of the insurance company, which does not interfere in the affairs of the client (society) until an insured event occurs. In this model, it is wars and epidemics that serve as insurance events. In other words, it is the pandemic situation that should have been the occasion for the state to intervene decisively from the outset, rather than to leave this situation to chance.

In our country, everything has been and has been exactly the opposite. We are a country with deep traditions of «totalitarianism», that is, a powerful centralized state with a hypertrophied social sector and highly pompous social obligations. States of this model have a high mobilization resource, and emergency situations here are not an insurance force majeure, but the norm, which even has a structural and functional materialization (the Ministry of Emergency Situations). It should be expected that our political and legal nature would prompt a prescriptive, coercive solution to the problem. As in China.

Meanwhile, our state has chosen a liberal strategy to combat COVID-19. The population was given the freedom to vaccinate or not to vaccinate, the freedom to choose a vaccine within the available choice. Over a year and a half an intensive explanatory information campaign was carried out, during which a mass of authoritative medics, media figures and, most importantly, led by the President of the Russian Federation, who repeatedly stated the inadmissibility of forced vaccination of the population.

The answer to the question of why the authorities needed such a sharp and unexpected bias toward 
liberalism in the issue of organizing the fight against the corona virus, we leave out of the parenthesis. This is the competence of political science. The competence of sociology is to answer the question of what was the public response to this communicative message and what this response means in the broader context of the state of political culture.

The content of the communicative message proclaiming «freedom of inoculation» and an «exhortatory» informational policy can be expressed in the following slogan: «We believe that you, our population, are composed entirely of rational, sane and humane citizens»». Because only rational beings are worthy of freedom and sane to be exhorted.

However, the hypothesis contained in this message is losing validity by the day. Immunization statistics show a stubborn reluctance of the population to cross the $50 \%$ threshold of population immunity. Not even the application of the «Chinese option» to «some categories»" of citizens saves the day. «Some categories» is a Jesuit wording, since logically all categories of citizens are «some» and thus explicitly contains the possibility of applying a totalitarian approach to the entire population as a whole. FOM polls (https://covid19.fom.ru/post/borba) show that the proportions of vaccination enthusiasts, hesitant and convinced «anti-vaccinationists» are approximately onethird each; and these proportions do not change significantly, regardless of the ingenuity of social advertising or the authority of the many and varied social advertisers led by the President.

Now, after two years of the pandemic, the «nonpublicity argument» is almost completely invalid. They talk about the danger of the disease and the benefits of vaccination dozens of times a day. Everyone who is sane, reasonable and humane («Take care of your neighbor!») has already been imputed, reasoned and voluntarily vaccinated.

The other third of those who hesitate are lured like capricious children by various «candies» and caught in train stations, airports, and supermarkets. I suspect the next vaccination booths will open in public toilets. Joke. «Capricious children» is not a metaphor, and if it is, it is not an artistic metaphor, but a methodological one. Because the social behavior of this category is characterized by limited sanity, limited rationality, and limited humanity. Some of them have managed to be captured and vaccinated forcibly as "some categories», but it is doubtful that this has added to this one-third covid-enthusiasm.

But of greatest interest, in our view, is the third social group, which a year earlier was called «coviddissidents», and now the noun «antivaxxers» is more often heard. The first name is more accurate, since «dissident» originally meant protesting religious selfdetermination, and the transition of this group from the category of «doubters» to «convinced opponents» did not happen immediately. Nowadays, only a lazy person does not apply the word «sect» to them, so the trope «convinced adversaries» emphasizes conviction rather than anti-vaxxerism. The terms «covid-dissidents» and «sect» will be used in the future by us as well. And here's why.

Doubt is more energetically costly than faith. One can doubt W. James's concept in many ways, but his observation that Cartesian doubt inevitably evolves into faith is difficult to challenge, since behind this mechanism lie biological regularities rather than the vicissitudes of interpretation [7, pp. 223-238].

Therefore, the split, in academic parlance differentiation, is an objective historical inevitability, which cannot be finally overcome by any propaganda tactics, no persuasion and «candy». Certain variations are possible only taking into account the socio-cultural specificity of the macro-community. The element of the cultural matrix «freedom (will)» is filled in different ways in different peoples, in different regions.

As far as Russia is concerned, differentiation according to the criterion «I believe/don't believe» is exactly a Schism, no matter whether we are talking about bicuspidism or about the benefits/ harms of vaccinations. Literally before our eyes, another sectarian movement is crystallizing, with all the ontological signs of historical inevitability. Of course, Victoria Bonya (activist of the anti-vaxxer movement) is nothing like Feodosia Prokopyevna Morozova - neither intellectually, nor willfully, nor behaviorally. But if the pandemic epic continues for a few more years, as most experts predict, it is more than likely that there will be «passionist» and «innocent martyrs», and even suicides based on quasireligious intransigence.

Naturally, covid-dissident fanaticism is heterogeneous in its social composition. The core of this group is, or in the long term will be, the «real raving» (V.S. Vysotsky's accurate and concise term), around whom the main social body of the «sect» will be formed by means of passionate induction.

During the implementation of our «interview + observation» case study, we encountered only two cases of complete social insanity, which is much less than the margin of error. However, such cases cannot be neglected, because such situations reflect not only the social mechanism of passional induction, but also the psychological mechanism of motive crystallization. Both cases of coercion to wear a mask in public places were accompanied by a sharp increase in the degree of excitement and aggression; literally before the eyes of the observer, the social type Naughty (Shalopay) was transformed into the social type Extremist.

Unfortunately, the toolkit did not allow us to trace the further trajectory of the fate of these individuals specifically, but we can be quite sure that the repetition of such situations will only reinforce the stigma of the Martyr in them. In I. Goffman's system of concepts, we have actually observed the beginning of the transition 
from the second stage of stigmatization (awareness of oneself as a bearer of a socially treacled predicate) to the third (provocation of the social environment to the application of sanctions).

In addition, what remains unknown in the cases described is the socio-energetic potential of the covidextremists observed. Is their social habitus capable of covering any significant social ground? Do they possess the charisma of archpriest Avvakum? The answer, which is usual for social singularities, will become known later, for a passionarius always stands out from the social background - otherwise it is not a passionarius. But then, which is also usual for social singularities, it will be too late.

Covid-extremism is an example of «toxic» passionarity. But it is still passionarity, regardless of the modus. Regional specifics (we are talking about the Republic of Khakassia and the south of Krasnoyarsk territory) on the discussed indicator is that passionarity here is subject to constant erosion - the most active and enterprising social atoms, carriers of human capital, in most prefer to migrate to big cities, to capitals, even abroad. This is despite the fact that the generation of such carriers has a quite satisfactory scale and is even productive. Partially digressing from the topic, I would like to give only two examples of such exceptions to the general rule.

First. In 2021 within the framework of the program «Leaders of Russia» the representative of the Republic of Khakassia E. Seryakova was the winner of the «Public Administration» track and a finalist in the final competition. In her interview, which makes this example a pleasant exception, she emphasized that she did not plan and does not plan to move to any more prestigious region in the future.

The second example. Vissarion (S. Torop), who created the «Church of the Last Covenant» sect, is also a local «cadre». In the years of his greatest popularity, having communities of adherents even in the U.S. and, therefore, the opportunity to migrate to more «greenhouse» conditions, he nevertheless chose to migrate to the taiga area of the Kuragino District in the south of Krasnoyarsk Territory.

The cases of covid-extremism cited above fit into the general picture of a lack of passionarity in general. Our surveys showed that the overwhelming majority of respondents were noticeably terse in their attitudes toward the pandemic, fitting into three or four lines of text. Phrases like «I don't know», «in general everything was fine», «somehow we didn't notice» were very common. Irritation and optimism were manifested in very restrained forms. In 42 cases, repetitions and tracing of other answers were found - this is a pure manifestation of the social type of Naughty. All of the above are, to a greater or lesser extent, manifestations of social homeostasis. Had our survey taken place in the 18th century, we would have unmistakably identified this position as the social worldview of a serf peasant and, in the 17th century, that of the passive Nikonian majority.

Now more about the survey. The content of the interview was formed of three thematic blocks. The first block involved the respondents' reflection of the socioeconomic status of their families. In comparison with the national statistics, there was nothing unexpected. Those whose parents worked in the spheres of small and medium business confessed of worsening financial maintenance («...my father's car shop was almost ruined, it was the height of the season, and people started driving less» - Vladimir P., student of KhSU, law, here and further the grammar is authentic). Families whose breadwinners represented professions that were restricted were also affected. «My mother works as a speech therapist, ...my family's financial situation has worsened due to the fact that my mother's job has been reduced.» (Tamara Z., student at KSU, SMU, fatherless family).

Representatives of families whose breadwinners fell into the categories of occupations that retained the same amount of work and wages relayed a sense of calm in the essays. «Our financial condition has improved, since my dad works on a rotational basis... And my mom and I work at an enterprise that is considered a supply company, the quarantine has not touched it» (Kristina D., economics). «Parents work in the budget sphere, somehow we did not feel the deterioration of our financial situation...» (Roman K., law). «I did not notice any poverty, it was fine, I guess. Only we went shopping less often. It is unclear why...» (Konstantin R., 11th grade).

A certain degree of destabilization of the material situation of families was shown by $72.3 \%$ of the respondents. But the contextual analysis showed that the majority of «well-off» respondents have rather superficial ideas about the state and dynamics of the family budget. It must be said that the stigma of carelessness was found in a relatively small number (26 interviews); many full-time students are engaged in parttime work, i.e. they also act as «auto-capitalizers» (74 respondents).

The second thematic block was devoted to the assessment of the emotional-subjective state of one's own and (implicitly) one's relatives. The point is that the range of emotional states caused by the need for self-isolation and other restrictive measures can be rather wide. Possible irritation, indignation has already been mentioned above. On the «positive» end of this conditional scale there can be, for example, «to finally enjoy myself and my close people»; for people of a creative type there is also an additional resource of time to plunge headlong into creativity without being distracted by a work routine.

Psychological reactions to limitations, reflected in the interviews, were in the negative part of the spectrum 619 times, a neutral tone («...nothing much has changed...» Anton Z., student) was noted in 511 texts, positive - in 86. The word «annoyed» was mentioned in 347 essays, 
«couldn't wait» in 118 cases, and «fed up» in 243. It is easy to see that for young people, the most mobile, active part of the population, forced restrictions were mainly a cause of repression. However, there were no overtly extreme reactions, which has already been noted above in connection with the deficit of passionarity. The most frequent cause of dissatisfaction was the difficulty of face-to-face communication with friends and too long face-to-face communication with relatives. But this should be attributed to the problems of the institution of the family, which is indirectly relevant to our topic.

Directly related to the theme is the third cluster, which invited respondents to comment on how they thought the resistance to the virus should have been organized. The clichéd expectations for the young age cohort - freedom-loving, hypertrophied energy, curiosity, striving for originality at any cost, distrust of the opinion of older people - did not quite come true.

First, we expected a fairly large number of Coviddissidents, not only because of libertinism, but also because young people objectively get Covid-19 less often and more easily than older age cohorts. Not so! For the entire sample, there were only two people with an openly dissident worldview. An exception, worthy of mentioning: «...Personally I do not believe in coronovirus, yes maybe there is influenza, but I do not think that is so serious, especially when a person dies in hospital because of ordinary cancer, and he was prescribed coronovirus and not give relatives to bury in peace, but only at a distance, without providing any documents and tests. Why, to make money, this is not the first time I've heard of such a case. It's just that the state is doing something of its own there (scheming) and they decided to lock us all up at home». (Nadezhda G., student).

The hope of encountering a large number of idealistic vaccination enthusiasts has not been fulfilled either. In only 41 interviews does one encounter an existential motif like the following: «...humanity needs to experience such a stressful situation just to realize the value of being» (Alyona N., student, social work).

The adolescent maximalism in the statements of course manifested itself, but not in personal freedomloving or liberalism as a worldview position, but rather in a commitment to strict disciplinary measures - «shut down, react faster», «do not hesitate», «criminal punishment for violating the regime». Such supporters of the «totalitarian» scenario of combating the coronavirus among the young people surveyed were $73 \%$.

Such a distribution does not look unexpected, if we take into account that we are talking about a provincial city and provincial youth [8]. In large cities, where young passionaries migrate, including from our province (the Republic of Khakassia), a slightly different spiritual and social situation, there is a higher concentration of liberal thinking intelligentsia, so youth bravado and protest activity is not uncommon.
In the provinces, on the other hand, there remain those with meager energy potential who find it difficult or even dangerous not just to speak out, but simply to speak anonymously, and not just to speak out, but to even think about an elementary problem. Here it is easier to retransmit social attitudes, subtly indoctrinated by socializing instances.

However, homeostasis, a deficit of social energy, does not always mean a deficit of the communicative complexity of the system. On the contrary, the energy crisis of the system is often caused by an excessive layering of meanings in the structure of the message. [9, p. 89] An abstract example: the crisis of modern theater is precisely caused by the fact that the content of classical dramaturgical works does not «fit» more and more new subtexts of new and new directors-innovators.

This was also the effect found in our case study. The pre-study in the form of observation showed that attitudes towards pandemic control measures at the level of opinion and social action are not just different, but are in inverse proportion, which correlates with other studies [10]. Approximately two-thirds $(68.4 \%)$ of the previously surveyed respondents, when entering educational institutions and classrooms, did not burden themselves with wearing masks. The observation was not only open, but even experimental-declarative, since it was accompanied by an explanation of the fixation of cases of covid neglect. But even after the observer's faceto-face contact with classrooms of students, college students, and even schoolchildren, some of the latent covid dissidents did not fully cover their respiratory organs, some left the mask on their chin (62), and another part (17) did not wear personal protective equipment at all, citing its absence, but refusing to leave to acquire it. The most frequent argument was «I was vaccinated». The counter-argument that a vaccinated person can still be a carrier of the virus and pose a danger to others had no visible effect, and in 3 classrooms it even caused hilarity.

The established discrepancy between the results of the survey and observation, in our opinion, does not mean a methodological contradiction, but, on the contrary, shows a more complex composition of the communicative behavior of the studied population. The request for stricter restrictive measures, on the one hand, and the demonstrative unwillingness to take such measures in relation to oneself, on the other hand, as it turned out, may well coexist even in several social types of personality. As applied to the situation, we have distinguished such types as the Naughty (Shalopay), the Quiet Saboteur, the Rebel-Hysteroid, the Obedient, and the Enthusiast.

Their detailed socio-psychological study and description is the subject of further publications. Here we would like to draw attention to the extent to which this pool coincides with the set of strategies of political loyalty manifestation. Indeed, it has long been no secret to specialists that there is a whole gradation in the content of the concept «loyalty» from momentary sympathy, 
through cynical gain, habits of submission and mimesis, to loyalty. The antonym of «disloyalty» is just as varied in content - from momentary irritation to fanatical extremist pathos. [11, p.97]

Meanwhile, we should be prepared for the fact that the distribution of these social types in the social space is also uneven [12]. How to diagnose the typological proportions and their local concentrations? The technology of questionnaire survey as applied to this problem, unfortunately, has certain limitations. There is no and cannot be an unambiguous answer here. But the correlations between covidual behavior and the political position of individuals and social groups revealed in our study allow us to give a clearer and more detailed description of the situation.

\section{CONCLUSION}

Fresh news: there is a new strain of COVID-19 virus, «omicron», which according to some estimates is even more dangerous than "delta". And speculation around this topic has already begun. Some epidemiologists and government officials express confidence that the danger is exaggerated and will be easily overcome (https://solenka.info/v-britanii-prizvali-ne-pugatsjanovogo-omikron-shtamma-koronavirusa-sars-cov2.html). Being a sociologist, but not an epidemiologist, I will nevertheless make a prediction: the new Omicron strain will repeat the same scenario as the Wuhan and delta strains. Globally, nationally, and regionally.

The results of our research, in particular, lend credence to this prediction. Namely: not only the virus itself, but also the patterns of its spread, and the morphology of the population's reactions, and even the political response to the situation have not only a social but also a biological character. Distribution according to scenarios of social behavior, crystallization of social types, including such relativistic typologies as the one proposed above, is an objective social fact, determined not only structurally and functionally, but also medicobiologically.

\section{ACKNOWLEDGMENTS}

The reported study was funded by RFBR according to the research project № 19-011-00365

\section{REFERENCES}

[1] K. Schwab, T. Malleret, COVID-19: The great reset. World Economic Forum 91-93 route de la Capite CH-1223 Cologny/Geneva Switzerland, pp. 212 (2020).

[2] N.V. Latova, Situation in the country and prospects for its development through the prism of public opinion during the pandemic, in: Sociological Studies, 4, (2021), pp. 37-49. https://doi.org/10.31857/S013216250013734-0.
[3] T. V. Shipunova, Criminal activity of the population during the pandemic: preconditions, situation and possible risks, Vestnik (Herald) of Saint Petersburg University. Sociology, 14(2), (2021), pp. 143-154.

[4] Russian Statistical Yearbook: Statistical collection (2019).

[5] A. V. Karavay, Assessment of the relationship between health and employment of Russians in the late 2010s, in: Sociological Studies, 7, (2021), pp. 61-72. https://doi.org/10.31857/S013216250014454-2.

[6] S. G. Klimova, I. A. Klimov, Experience of Russian companies' transition to remote work under pandemic conditions, Sociological Studies, 7, (2021), pp. 50-60. https://doi.org/10.31857/S013216250014470-0.

[7] W. James, The Will to Believe, p. 431 (1997).

[8] A. Shor-Chudnovskaya, Young Russians' View of Their Family's Soviet Past: Nostalgic, Post-Utopian or Retrotopian? In: Mir Rossii, 27(4), (2018), pp. 102-119. https://doi.org/10.17323/1811-038X2018-27-4-102-119.

[9] S. E. Martynova, P. V. Sazonova, Public communications during the COVID-19 pandemic: assessments of Russian citizens, in: Bulletin of Tomsk State University: Philosophy. Sociology. Political Science, 62, (2021), pp. 87-101. https://doi.org/10.17223/1998863X/62/8.

[10] A. V. Rezaev, M. L. Ni, Latent student discontent under academic capitalism: a comparative analysis of ideal types of students of humanities and technical specialties, Mir Rossii, 29(2), (2020), pp. 49-71. https://doi.org/10.17323/1811-038X-202029-2-49-71

[11] S. Y. Barsukova, A. V. Zvyagintsev, L. S. Laptieva, Experience of youth participation in election campaigns and its on their civic position, Sociological Studies, 7, (2021), pp. 90-100. https://doi.org/10.31857/S013216250015537-3

[12] E. S. Bogomjakkova, E. E. Popova, Compassion fatigue» in the practices of media consumption (on the example of attitudes to the problematization of COVID-19 distribution), in: Sociological Studies, 6, (2021), pp. 46-56. https://doi.org/10.31857/S013216250012269-8 